\title{
EL OBISPADO DE CARTAGENA-MURCIA \\ Y SU CABILDO CATEDRALICIO \\ FORMACIÓN Y EVOLUCIÓN \\ EN EL TRANSCURSO DE LA EDAD MEDIA
}

\author{
MARÍA JOSÉ Olivares TEROL \\ Universidad de Murcia
}

\begin{abstract}
SUMARIO
1. Período de formación.- 1.1. ¿De quién era sufragánea?.- 1.2. La división de la diócesis.- 2. Los miembros capitulares: sus funciones.- 2.1. Las dignidades.- 2.2. Los canónigos.- 2.3. Racioneros.- 2.4. Mediorracioneros.- 2.5. Otros prebendados y servidores.- 2.6. Otros cargos de tipo administrativo.- 2.7. Los oficiales de la escribanía y audiencia episcopales.3. Sede vacante.
\end{abstract}

\section{PERÍODO DE FORMACIÓN}

Un modo de definir a cualquier cabildo catedralicio sería, por ejemplo: "Una institución eclesiástica diocesana que sigue en importancia al obispo, quien no sólo debe escuchar su consejo y recabar su asentimiento para el gobierno y organización de la iglesia a él encomendada, sino que de él selecciona sus principales consejeros y servidores para la administración del obispado, siendo el cabildo de la catedral quien, de forma colegiada, cubre las necesidades de la sede vacante y el que cuenta con legítimos derechos canónicos reconocidos en el IV Concilio de Letrán para elegir al candidato más idóneo que debe ocuparla"'.

\footnotetext{
'Definición dada por José Rodríguez Molina, El obispado de Baeza-Jaén. Organización y economía diocesanas (siglos XIII-XVI), Jaén, 1986, p. 61.

"Anuario de Estudios Medievales", 27 (1997)
} 
De su período de formación y organización no son muy abundantes las noticias. Su sede se sitúa en un primer momento en la ciudad de Cartagena, desde que en 1250 Inocencio IV decide reinstaurar de nuevo el obispado, siendo nombrado como su primer obispo fray Pedro Gallego, confesor del futuro Alfonso X. Este otorgamiento se produce tras las peticiones hechas por el rey Fernando III y su hijo Alfonso, que desean el restablecimiento de las diócesis episcopales en los territorios anexionados tras la Reconquista. A ello les mueve, junto a motivos puramente religiosos y de cristianización de los territorios, causas de orden político y de intervencionismo en las instituciones eclesiásticas: control sobre los cabildos catedralicios, promoción y nombramiento de obispos, abades, etc. Esto será una constante en los siglos sucesivos, ocasionando en determinados momentos fricciones entre la Santa Sede y la Corona.

Alfonso X entregó como donación a la nueva Sede cartaginense una cantidad de 10.000 monedas de oro anuales situados en rentas reales y repartidas de la siguiente manera:

-5000 en las rentas de Murcia,

-1000 en las rentas de Elche,

-2000 en las rentas de Orihuela,

-2000 en las rentas de Lorca.

Incluyéndose además la potestad de recaudar los diezmos del obispado $^{2}$. Sin embargo, las rentas reales no eran todavía lo suficientemente amplias como para cubrir aquella cantidad y se transformó en la percepción de diez alquerías en la huerta de Murcia. La escasa población y las dificultades para su explotación, hicieron poco rentables las alquerías y de nuevo se realizó una permuta, en 1272, por 650 tahullas y 1.500 maravedís situados en las rentas reales de Murcia.

Con esta última concesión la Iglesia de Cartagena se convirtió en una gran propietaria de inmuebles urbanos y aseguró la percepción de una parte de las rentas del artesanado de la ciudad cuando la Corona cedió todos sus censales murcianos para asegurar el pago de los 1500 maravedís dotales. Otras donaciones completarían este proceso que quedaría finalizado en el siglo XIV con la obtención de dos señoríos mudéjares, Alcantarilla y p. 20 .

${ }^{2}$ Juan TORRES FONTES, El obispado de Cartagena en el siglo XIII, "Hispania", XIII (1953), 
Alguazas, que permitieron al obispo y cabildo convertirse en señores jurisdiccionales ${ }^{3}$.

A pesar de ser ésta su sede oficial, sin embargo, los tiempos requerían la presencia del cabildo junto a la de su obispo, que pasaba la mayor parte del tiempo en Murcia capital. Debido a que Cartagena no representaba un papel importante ni estratégico para el reino castellano y considerando que el nuevo centro político, social y económico se encontraba en Murcia, éste era también el lugar que debía ser sede del poder eclesiástico.

Será antes de que finalice el siglo XIII cuando se produzca, de un modo oficial, el traslado de la Sede episcopal desde la ciudad de Cartagena hacia Murcia. El 13 de septiembre de 1289 Nicolás IV otorga una bula para que se pueda proceder al cambio y dos años más tarde (26 de mayo de 1291), el rey Sancho IV autoriza también dicho traslado ${ }^{4}$.

El cabildo cartaginense se reinstaura, al igual que sucede con la mayor parte de los situados en el sur de la Península Ibérica, no existiendo un período de continuidad desde la época visigoda hasta la mitad del siglo XIII; muy al contrario de lo que sucederá en la zona norte, en donde se puede apreciar la evolución que sufrió dicha institución.

$\mathrm{Si}$ en un principio los cabildos tenían una función cultual, de apoyo y ayuda al obispo, sin un patrimonio propio ni una separación jurídica; será a partir de siglo XII y principios del XIII cuando se produzca una consolidación institucional de los cabildos catedralicios. Durante estos años se separan las mesas capitular y episcopal y con ello existe un fortalecimiento de dicha institución como ente autónomo. De nada sirvió la reforma gregoriana (1050-1200) que intentó poner freno a las tendencias secularizantes que se estaban produciendo en el seno de los cabildos, siendo en las centurias siguientes cuando se constituyan dichas instituciones con todos sus derechos y prerrogativas.

Pues bien, esa evolución paulatina que se realiza en las diócesis del norte (León, Lugo, Astorga, Oviedo, etc.) no se plasma del mismo modo en la Sede cartaginense ni tampoco en las otras de la zona sur. En el momento de su restauración ya se ha desarrollado la mayor parte del proceso de

\footnotetext{
${ }^{3}$ Miguel Rodríguez Llopis e Isabel García Díaz, Iglesia y sociedad feudal. El cabildo de la catedral de Murcia en la Edad Media, Universidad de Murcia, 1994, p. 22.

${ }^{4}$ Abelardo Merino Álvarez, Geografía histórica del territorio de la actual provincia de Murcia, Murcia, 1981, p. 163.
} 
secularización de los cabildos catedralicios y son varios los ejemplos a imitar. Tal sería el caso de la Iglesia de Baeza, surgida hacia el año de 1230 y cuyo cabildo catedralicio fue organizado a la manera de la Iglesia de Toledo, de la cual era sufragánea ${ }^{5}$.

En principio los límites del obispado coincidieron con los del Reino de Murcia en esa época. Por el NE incluía el término de Alicante y el valle de Ayora hasta el río Júcar mientras que por la zona occidental abarcaba los términos de Peñas de San Pedro, Caravaca y Lorca hasta el mar. El trazado por la zona oriental no cambió aunque, a principios del siglo XIV, la Corona de Aragón se anexionó los territorios de la zona sur de la actual provincia de Alicante. Ello supuso que Orihuela, Alicante, Elche y otras poblaciones permanecieron durante la baja Edad Media bajo el señorío del rey aragonés, pero sometidas a la jurisdicción eclesiástica de un obispo castellano. La zona occidental del obispado se modificó en el propio siglo XIII para incluir las encomiendas orientales de la Orden de Santiago (Yeste y Segura de la Sierra) y, más al sur, territorios del reino de Granada como Huéscar, Galera y Orce que, ocupadas y posteriormente perdidas por los castellanos, no llegarán a integrarse en el obispado hasta el siglo $\mathrm{XV}^{6}$.

\section{1. ¿De quién era sufragánea?}

La Diócesis de Cartagena-Murcia varió a lo largo de su historia en la cuestión de su dependencia o independencia con respecto a otras Iglesias metropolitanas. Antes de la llegada a la Península Ibérica de los pueblos germánicos, Cartagena se había configurado como una destacada e importante sede metropolitana. Con el tiempo dicha capitalidad eclesiástica pasó a Toledo, antigua sufragánea suya, y Cartagena fue decreciendo en importancia hasta producirse su desaparición.

Una vez queda resuelta su restauración, se plantea el que sea dependiente de Toledo o de Tarragona, ya que ambas sedes metropolitanas se la disputan. Toledo la quiere bajo su dirección alegando su antiguo pasado en común. Tarragona se basa en diferentes derechos aduciendo algunas promesas reales y del papado; aunque en realidad, las relaciones apenas se

\footnotetext{
${ }^{5}$ Rodríguez Molina, El obispado de Baeza-Jaén, p. 62 22.

${ }^{6}$ Isabel García Díaz, Documentos del siglo XIV. Archivo Catedral, Murcia, 1989, pp. 21-
} 
habían producido entre dichas diócesis a lo largo de la historia. Para dar por finalizada esta disyuntiva Inocencio IV da como solución la dependencia directa de Cartagena a la Santa Sede y sin tener en consideración las aspiraciones de Toledo ni de Tarragona ${ }^{7}$. Dicha situación se mantuvo hasta la llegada de Rodrigo Borja al papado bajo el nombre de Alejandro VI, que crea el arzobispado de Valencia en 1492 y a Cartagena la deja anexionada y dependiente de él.

A pesar de su dependencia de Valencia, sin embargo, la mayor parte de sus relaciones y contactos fueron establecidos con el Arzobispado de Toledo y, por extensión, con las demás diócesis de Castilla. Hay una correspondencia muy fluída con Toledo y una asistencia a las congregaciones que se celebran en esta zona. La situación con respecto a Valencia no duró por mucho tiempo y los pleitos y las disputas, en ocasiones sangrientas, con Orihuela, que pretendía erigirse como sede catedralicia e independizarse de Cartagena, fueron constantes. A raíz de esta insostenible situación y de un modo definitivo, Pio IV otorga a Orihuela el derecho a constituirse como sede episcopal con prelado propio en el año 1564; ella quedaba anexionada al Arzobispado de Valencia mientras que Cartagena pasaba al de Toledo.

\subsection{La división de la diócesis}

La Diócesis cartaginense estaba constituída por territorios pertenecientes a dos Coronas diferentes, la castellana y la aragonesa; siendo los deseos de independencia de la parte aragonesa muy fuertes y violentos, especialmente a finales del XV y principios del XVI. Tras la creación del arzobispado de Valencia, a Orihuela le fue concedida una vicaría dependiente del obispo de Cartagena; pero tal decisión de Alejandro VI no fue aceptada $\mathrm{y}$, durante largos años, se sucedieron enfrentamientos dialécticos y físicos entre las gentes de ambas zonas.

En 1510 Julio II, debido a la petición de Fernando el Católico, expidió una bula por la cual erigía a Orihuela como sede catedralicia, aunque seguía bajo la jurisdicción del Prelado de Cartagena ${ }^{8}$. Orihuela consigue que su colegiata sea proclamada como catedral y crea para ello una mesa capitular, un cabildo catedralicio propio y todos los servidores precisos para

\footnotetext{
${ }^{7}$ TORRES FonTES, El obispado de Cartagena, p. 25.
}

${ }^{8}$ Merino Álvarez, Geografía histórica, pp. 330-331. 
ocuparse de los cuidados y oficios divinos en la Catedral. A pesar de todo ésto, los enfrentamientos y disputas no cesaron, pues ellos querían la independencia total y no seguir bajo las órdenes del obispo de Cartagena.

Serán frecuentes los requerimientos y mandatos dados por los diferentes papas, entre ellos León X y Clemente VII ${ }^{9}$, para intentar poner orden entre las dos partes involucradas, aunque los llamamientos a la concordia no surgieron efecto durante estos años. La situación quedó zanjada en 1564, cuando Pío IV la separa definitivamente otorgándole su propio prelado, así como las tierras de su jurisdicción. Pero no por ello los litigios cesan totalmente, si bien serán diferentes los motivos. Queda una diócesis mermada territorial y económicamente y de cuya situación harán continua referencia los prelados de la segunda mitad del XVI.

\section{LOS MIEMBROS CAPITULARES: SUS FUNCIONES}

El número de los componentes del cabildo catedralicio cartaginense varió un poco desde la fecha de su restauración en el XIII hasta el XVI. Si bien el primer obispo de Cartagena, Pedro Gallego, estuvo acompañado por un capítulo se desconoce la primitiva organización; será en el siglo XIV cuando se produzca un arreglo que continuará, fundamentalmente, durante varios siglos.

En 1315 Juan Muñoz, quinto obispo de la Diócesis, estructuró el cabildo del siguiente modo: 6 dignidades (deán, chantre, arcedianos de Cartagena y de Lorca, tesorero y maestrescuela), 8 canónigos y 12 racioneros. Años más tarde, en 1366, el obispo Nicolás de Aguilar hizo en su obra Fundamentum Ecclesiae algunas modificaciones: 6 dignidades, 8 canónigos, 8 racioneros y 8 mediorracioneros. En 1447 Diego de Comontes hace otra modificación que se mantendrá durante toda la Edad Moderna: 6 dignidades, 8 canónigos, 8 racioneros y 12 mediorracioneros.

El número de capitulares que disponía el cabildo de la Catedral era más bien escaso y pobre en relación a la cifra que integraban otras diócesis. Así el cabildo de Oviedo en 1301 contaba con 11 dignidades, 38 canónigos y 22 racioneros; cantidad que aumenta a finales del siglo XIV, pues de los

\footnotetext{
${ }^{9}$ Archivo Catedral de Murcia, Ascensio de MoRales, Libro de bulas y privilegios reales, 221 , fols. 406 r. -414 v.; 223, fols. 352 v. y ss.
} 
38 canónigos anteriores se pasa a $50^{10}$. Otro ejemplo sería el cabildo de la Catedral de Baeza que, en el siglo XIV, contaba con: 8 dignidades, 21 canónigos prebendados, 6 racioneros enteros, 12 mediorracioneros y 12 canónigos extravagantes ${ }^{11}$. El número de componentes variaba, en esencia, del potencial económico de la corporación capitular y la diócesis cartaginense no era, precisamente, de las más opulentas del territorio peninsular.

Dentro de los propios miembros del cabildo existía una marcada distinción y estructuración jerárquica, donde cobra una gran importancia el nivel económico y la categoría social de cada uno de ellos. Así tenemos: las dignidades, los canónigos y los racioneros; y tras ellos, hay un grupo variado de personas que sirven de diferentes modos dentro de la institución capitular. La posesión de uno de los beneficios mayores se conseguía mediante la elección por el obispo, por los miembros capitulares, o por ambos conjuntamente; también su nombramiento podía venir directamente de la Santa Sede.

Además de estos 34 capitulares, al servicio del culto en la Catedral había dos beneficiados curados que administraban los sacramentos en todo tiempo, dos beneficiados: uno que tenía como misión principal decir y cantar el Evangelio (evangelisterio) y otro encargado de decir y cantar la Epístola (epistolero). El número de capellanes, en un principio, era de 16 pero en 1543 fue aumentado a 24. Estos tenían que asistir al coro todas las horas canónicas, ganando por distribución cotidiana el alimento de sus beneficios.

El número total de personas que forzosamente debían de residir en el coro para el servicio y ministerio del altar mayor de la Catedral era de 62 beneficiados. A todos ellos se unían más de 20 cantores que tenían asignados diferentes salarios, dependiendo de su voz y habilidad para el canto, aportados entre las mesas capitular, episcopal y la fábrica. También había 12 mozos o infantes de coro escogidos por sus buenas voces para el servicio del coro, altar mayor y capilla de música ${ }^{12}$.

El cabildo catedralicio celebraba sus reuniones, periódicamente, los martes y viernes de cada semana en la capilla de San Juan, en el claustro de la catedral de Santa María la Mayor. En las reuniones se trataban, sobre

\footnotetext{
${ }^{10}$ Soledad SuÁREz Beltran, El cabildo de la Catedral de Oviedo en la Edad Media, Oviedo, 1986, p. 65.

"Rodríguez Molina, El Obispado de Baeza-Jaén, p. 62.

${ }^{12} \mathrm{CM}$, leg. 31, n. 20.
} 
todo, temas económicos y rituales, aunque las primeras actas del cabildo conservadas datan de los últimos años del siglo XV.

La disminución de las atribuciones y competencias del cabildo en favor de un aumento, muy considerable, de las del prelado, dio lugar a las continuas quejas y oposiciones de los cabildos ante la Santa Sede y a una negativa a obedecer a sus prelados. Una de las competencias que más consideraban como propia (la elección de un nuevo prelado) fue uno de los puntos que más se resistían a abandonar y que más oposición causó entre los miembros capitulares.

Debido a las continuas ingerencias de los monarcas, cada vez más interesados en tener el control eclesiástico, y también por los intereses de la Santa Sede por dichas elecciones, en el siglo XV se perdió por completo dicha prerrogativa. Durante el período de Avignon la Iglesia se vio fuertemente centralizada y uno de los puntos en los que se centró el poder papal fue en la reservación de las elecciones episcopales, en detrimento y perjuicio de los cabildos catedralicios. Esa actuación por parte del papado chocaba de frente con las intenciones del poder real que intentaba controlar la situación, si no de un modo directo, sí indirecta y diplomáticamente.

A pesar de que en el Concilio de Basilea (1433) quedaba establecida la libertad de los cabildos para elegir a sus prelados sin la intervención del papado, que solamente lo haría por un motivo serio e importante, este decreto no se manifestó en el reino de Castilla, sino que la Monarquía siguió actuando como provisora de los nuevos prelados en las diferentes sedes episcopales que quedaban vacantes ${ }^{13}$. Esto variaba sustancialmente del rey que estuviese en el trono y de su mayor o menor capacidad de mando y autoridad para imponerse en las elecciones episcopales. En momentos de confusión política o debilidad real los cabildos actuaban con una mayor libertad para elegir a sus prelados. También se debía tener muy en cuenta los intereses del papado, pues podía promover a alguna persona a las sedes vacantes y chocar de frente con los cabildos oponiéndose a tal decisión.

Tal situación fue especialmente conflictiva durante el reinado de Enrique IV de Castilla, donde se mezclaron motivos políticos y eclesiásticos. Así ocurrió en el caso de las Iglesias Catedrales de Sigüenza (muy codiciada

\footnotetext{
${ }^{13}$ Tarsicio de Azcona, La elección y reforma del episcopado español en tiempos de los Reyes Católicos, Madrid, 1960, p. 69.
} 
por su gran riqueza), Zamora, Oviedo, Tuy, Palencia, Cuenca, en las que el papa y el rey querían imponer a las personas elegidas por ellos ${ }^{14}$.

La prerrogativa para elegir los cabildos a sus prelados les será anulada al serles otorgado a los Reyes Católicos los derechos de presentación y patronazgo. El papa Inocencio VIII se los concedió el 13 de diciembre de 1486, y Adriano IV, en 1523, amplió esos derechos al emperador Carlos V para todas las iglesias de sus reinos.

\subsection{Las dignidades}

a) El deán

Era la más alta autoridad capitular, ocupando el primer lugar dentro de las 6 dignidades existentes en el cabildo catedralicio. La persona que había de ocupar dicho cargo tenía que ser clérigo presbítero y elegido de común acuerdo entre el cabildo y el obispo. En algunas catedrales para poseer dicha dignidad debía de haber sido con anterioridad arcediano, como en los cabildos de Avila, Burgos, Calahorra o Salamanca; en la Catedral de Oviedo también se mantenía dicha tradición, aunque no existía ninguna disposición por escrito al respecto ${ }^{15}$. En el cabildo que nos ocupa no se observa para nada dicha disposición y para acceder a una prebenda superior no se precisaba haber sido poseedor del otro grado más inferior.

Sus atribuciones fundamentales eran las de juntar y convocar a capítulo a todos los prebendados, siendo él quien lo encabezaba y presidía. Así mismo era el promotor y director de los negocios, tanto temporales como eclesiásticos del cabildo. Se ocupaba de controlar a los capitulares sus asistencias o no a las horas canónicas y a los oficios litúrgicos. En período de sede vacante él era el cabeza de la diócesis, apoyado en todo momento por el resto del cabildo. Se trataba de un cargo vitalicio y solía tener un coadjutor o persona que lo sustituía cuando no podía estar al frente de sus obligaciones personalmente.

\footnotetext{
${ }^{14}$ AZCONA, La elección, pp. 76-80.

${ }^{15}$ SuÁrez Beltran, El cabildo, p. 67.
} 


\section{b) Los arcedianos}

La segunda y tercera dignidad del cabildo la ocupaban los arcedianos de Cartagena y Lorca respectivamente. Para desempeñar tales cargos "combiene sean ordenados de Evangelio porque el dicho libro de fundamento e ynstitucion están y son obligados a vestirse con aparato todos los dias que el prelado çelebrare de pontifical y cantar el Evangelio"16.

Dichas dignidades eran otorgadas por el obispo sin necesidad de contar con el apoyo o decisión del cabildo, que sólo se ocupaba de ratificar lo acordado por el prelado. Sus labores eran, especialmente, de tipo administrativo. En un primer momento actuaban como delegados directos del obispo al realizar sus visitas por toda la diócesis; aunque esta función les fue mermada al cobrar importancia la figura del procurador y vicario general del obispado.

Presidían junto con el deán las sesiones del cabildo y actuando, en ocasiones, como presidentes de las mismas si el deán no acudía personalmente. Eran los encargados de salir a recibir al nuevo prelado hasta el Cantón de San Cristóbal, en la calle de Trapería, cuando éste llegaba por primera vez a la diócesis. Naturalmente debían de ir acompañados del resto de los miembros del cabildo, aunque eran ellos quienes entregaban la cruz al prelado para que la adorase. Para tal ocasión iban indistintamente un arcediano que otro.

En sus arcedianatos correspondientes actuaban como vigilantes y controladores de todo cuanto acaeciese: poseían facultad para juzgar a los clérigos que cometieran faltas e imponerles las penas correspondientes; siempre y cuando no se tratase de asuntos de mayor envergadura que precisasen la actuación directa del obispo.

c) El chantre

Cuarta dignidad capitular y su nombramiento también dependía directamente del obispo, siendo su misión primordial el coro. El chantre realizaba la selección de los aspirantes al coro, coordinaba a qué canónigo o racionero le correspondía durante la semana los oficios de misa, señalaba

\footnotetext{
${ }^{16} \mathrm{ACM}$, leg. 31, n. 20, 25-8-1581. Aunque las fechas corresponden al siglo XVI, se trata de disposiciones establecidas en la Baja Edad Media.
} 
los hebdomadarios o encargados de entonar los salmos, antífonas y demás cantos de cada semana. Debía procurar que el coro de la Catedral se encontrase en perfectas condiciones y que estuviesen los libros necesarios, los candelabros, el fuego durante el invierno. Tenía a su cargo todo lo referente a las procesiones y en las celebraciones solemnes era él mismo quien realizaba la dirección del coro sin delegarlo en el sochantre.

Del chantre dependía que la celebración de los diferentes oficios y procesiones saliesen correctamente y para ello debería, en teoría, de contar con una formación litúrgica y un perfecto conocimiento del latín ${ }^{17}$.

\section{d) El tesorero}

Era la quinta dignidad y también nombrada in solidum por el obispo. En muchos aspectos equivalía casi a un sacristán mayor. Su cargo cobrará mayor o menor importancia, siendo codiciado por el resto de los miembros del cabildo, según fuese la consideración del tesoro que debía guardar. En el caso de la Catedral de Murcia no debía de ser muy codiciado, a raíz de la petición hecha por Lope de Barrio, canónigo de Cartagena y procurador general en la Congregación del Santo Concilio Toledano:

El tesorero por fundamento de la dicha Iglesia tiene a cargo la sacristia y ha de pagar el sacristan y campanero, y luminarias y candelas para la Candelaria y palmas para el Domingo de Ramos, e quien barra la iglesia y las esteras que son necesarias.Y para ello se le anexó un prestamo de la Iglesia Mayor y otros anexos y todos los tesoreros pagaron todo esto por ser a su cargo hasta el tiempo de don Pedro de Medina, tesorero que dejó el prestamo y anexos a la fabrica. Y con esto se exoneró de toda la carga que es anexa a la dicha tesoreria y ansi lo han hecho los que despues han sido. Y la fabrica paga todos estos gastos no perteneciendole y siendo pobre en lo qual gasta más de 600 ducados cada año y el préstamo y anexos valdran hasta 300 ducados. Suplicase a V.S. Ilustrisima que se mande que el tesorero reasuma su anexo y pague lo que es obligado, conforme a la fundacion por razon de su dignidad, e que la Fabrica quede libre como lo era de los tales gastos ${ }^{18}$.

\footnotetext{
${ }^{17}$ SuÁREZ BELTRAN, El cabildo, p. 290.

${ }^{18} \mathrm{ACM}$. leg. 559 , n. 25. Petición dada en la Congregación del Santo Concilio de Toledo por el procurador Lope de Barrio, canónigo de Cartagena, 26-1-1583.
} 
El tesorero podía tener a un subsacristán para servir en la sacristía y ocuparse de las hostias y del vino para la Consagración, tanto en el altar mayor como en los otros de la Iglesia Catedral, tener cogidas las capas y ornamentos, cálices, corporales y otros objetos de plata y oro ${ }^{19}$. Contaba también bajo su supervisión y guarda todos los libros de coro, de la librería capitular y los relicarios. Personalmente se ocupaba de mantener encendidos los cirios del altar mayor, de las velas para el Obispo y los otros capitulares en ocasiones solemnes, de proveer el incienso para el incensario.

e) El maestrescuela

Sexta dignidad del cabildo catedralicio y elegida como las anteriores por el Obispo. Su función más destacada era la de tener una escuela para la preparación y enseñanza de los escolares en la facultad de las artes y del latín. El maestrescuela no tenía la responsabilidad directa de enseñar, sino que podía designar a un maestro para que lo hiciese en dicha escuela de un modo continuado. El salario que percibía el maestro provenía de las rentas del maestrescuela; si la dignidad quedaba vacante, su salario correspondiente se le debía seguir entregando.

También era el encargado de la corrección de los libros del coro, llevar un registro de las cartas y documentos que entraban o salían del archivo capitular. Tanto el maestrescuela como el tesorero recibían, además de sus correspondientes 2 canonjías y anexos, otra más en rentas de ración y destinada a los ministerios y oficios propios de sus dignidades. Esta tercera canonjía, dada tanto al tesorero como al maestrescuela, no era colativa ya que nunca podía estar libre ni constituir canónigo.

Se daba el caso de que, al quedar libre una de estas dos dignidades, también lo hacían sus anexos particulares, al igual que les sucedía a las demás dignidades. Al no ser colativas las terceras canonjías otorgadas y debido a que eran designadas a ministerios y oficios que no podían quedar libres, no quedaban vacantes tras la muerte de su titular. Estas dos terceras canonjías fueron separadas, por propia petición de sus titulares, de las otras dos que les correspondían a cada uno en fechas diferentes, siendo tesorero Pedro de Medina, el 11 de febrero de 1519, mientras que el maestrescuela lo hizo el 15 de junio de 1543 por modo de contrato oneroso que admitió el

\footnotetext{
${ }^{19} \mathrm{ACM}$, leg. 31, n. 20.
} 
cabildo y la jurisdicción ordinaria confirmó ${ }^{20}$. Las quejas fueron continuas por parte de los miembros capitulares, debido a que tenía que pagar la fábrica más dinero de lo que les reportaba de beneficios los préstamos y anexos correspondientes.

\subsection{Los canónigos}

Su número era de 8 miembros hasta que, durante la segunda mitad del siglo XVI, uno de los canonicatos fue anexionado al Santo Oficio por concesión apostólica de tal manera que sólo residían y había en el coro, en la última parte del siglo XVI, siete canónigos. Podían ser presbíteros o no, poseyendo además voz y voto en el cabildo ${ }^{21}$.

A lo largo del siglo XVI son instituídas 4 canonjías de oficio. Si bien tienen antecedentes dos de ellas, será a partir del Concilio de Trento cuando sean establecidas las cuatro: son las llamadas canonjías doctoral, magistral, lectoral y de penitenciaría. Para acceder a ellas era preciso reunir una serie de requisitos y superar diferentes pruebas. Las disputas por obtenerlas fueron muy diversas, no solamente entre los opositores, sino entre el propio cabildo y los prelados postridentinos: ambos alegaban tener derecho propio para elegir y nombrar a los diferentes canónigos ${ }^{22}$.

\subsection{Racioneros}

Eran 8 en la Iglesia Catedral de Murcia y tenían como obligación la residencia y asistencia continua al coro. Ocupaban por la jerarquía establecida las sillas, tanto en el coro como en el cabildo, posteriores a los canónigos; al igual que sucedía en los sitios de las procesiones. Podía ser racionero lo mismo un sacerdote que un diácono o subdiácono, así como celebrar misa en el altar mayor o en otras capillas de la Catedral.

Desempeñaban, al igual que las dignidades y canónigos, servicios para la Catedral y el obispo como por ejemplo: contador, mayordomo del punto, mayordomo del granero, etc. No poseían voz ni voto cuando se

\footnotetext{
${ }^{20}$ Archivo Municipal de Murcia, leg. 5, n. 15, p. 9.

${ }^{21} \mathrm{ACM}$, leg. 31, n. 20.

${ }^{22}$ Ver más ampliamente en el artículo de María José OLIVARES TEROL, Las canonjías de oficio y oposición en el XVI murciano, "Murgetana", 91 (1995), pp. 33-50.
} 
trataba de la elección de algunos beneficios, según constaba en una constitución dada por el obispo Nicolás de Aguilar. Sí tenían voz y voto en asuntos y negocios concernientes al cabildo.

Su elección era realizada por las dignidades y canónigos del cabildo mediante escrutinio; aunque en ocasiones podía darse el caso de que fuese impuesto por bulas y breves apostólicos o por influencia episcopal. Las apelaciones para poder participar y votar en las elecciones sobre prebendas son constantes y en los diferentes pleitos entablados siempre se les negó tal derecho, aunque podían asistir a las elecciones y votaciones como observadores. Esto podían hacerlo mientras no descuidaran sus obligaciones en el coro dejando solos a los capellanes. Dichos pleitos eran emprendidos por los racioneros y los mediorraciones conjuntamente, pues ambos grupos se consideraban discriminados dentro del cabildo.

\subsection{Mediorracioneros}

Eran 8 componentes en un principio hasta que, en 1447, Diego de Comontes aumentó el número a 12. Esta ampliación fue concedida por bula plomada de Eugenio IV y confirmada posteriormente por Alejandro VI a petición de los Reyes Católicos ${ }^{23}$.

Estaban los últimos en el escalafón jerárquico del cabildo, tanto para las sillas del coro como para los asientos en el cabildo y, al igual que los racioneros, no poseían voz ni voto cuando se celebraban elecciones de prebendas. Tenían que ser clérigos presbíteros al tener que celebrar misa en el altar mayor "y hazer el oficio de sezerdote en el coro de la dicha iglesia cathedral en todas las oras canonycas, ansi diurnas como noturnas"24. Las vacantes eran proveídas entre el obispo, deán y cabildo, según un breve concedido por Alejandro VI, mediante el sistema de cédulas y escrutinio ${ }^{25}$.

Aunque existía un estatuto en la Catedral por el que no podían recibir beneficios los descendientes de judíos ni moros, sino los cristianos viejos y tampoco podían ser hijos ni nietos de condenados por la Santa Inquisición, esto no se cumplía para la elección de los mediorracioneros ni tampoco para las otras prebendas, excepto para las canonjías de oficio donde

\footnotetext{
${ }^{23} \mathrm{ACM}$, leg. $46 \mathrm{~A}$, n. 4.

${ }^{24} \mathrm{ACM}$, leg. 31, n. 20.

${ }^{25} \mathrm{ACM}$, Ac. Cap. 1572-1576, fol. 310 v.
} 
sí seguía vigente. Según constaba en un breve dado por Alejandro VI, las personas designadas para mediorracioneros debían de ser expertas en canto y lectura, hábiles para el servicio en el coro y capilla de música. Generalmente se entregaban a los capellanes del número ya que para tal ministerio eran los más idóneos y percibían sus beneficios de la parte del deán y del cabildo.

Por el Fundamentum Ecclesiae, texto promulgado por el obispo Nicolás de Aguilar en 1366 y básico para conocer la composición del cabildo durante la baja Edad Media, los mediorracioneros estaban obligados a:

-Celebrar todas las misas conventuales y todos los oficios divinos de las horas que tocaban al deán y cabildo.

- Celebrar las misas de los reyes que eran conventuales y que se celebraban en el altar mayor; si ellos no las podían celebrar, tenían que dejar a otro sacerdote en su lugar y de este modo no caer en falta y pena pecuniaria.

- Además de esta función dentro de la Iglesia Catedral, debían de acudir a los rezos de letanías, a las procesiones y plegarias públicas que el cabildo realizase en algunos monasterios e iglesias parroquiales de la ciudad.

Las misas de reyes databan del siglo XIII. El rey Sancho IV hizo donación al obispo de Cartagena en 1289 del diezmo del almojarifazgo de Cartagena y Murcia, y a cambio se debía cantar diariamente una misa en el altar mayor de la Iglesia Catedral por el alma del rey Alfonso X, así como por la de todos los reyes de su linaje que le sucedieran. En pago de dichas misas dejaron ciertas posesiones para los miembros del cabildo:

- A cada una de las dignidades, 24 tahullas.

-A cada uno de los canónigos, 12 tahullas.

- A cada uno de los racioneros, 6 tahullas.

-A cada uno de los mediorracioneros, 3 tahullas.

Además, dejaron asignados 50.000 maravedís de renta para el cabildo y otros 50.000 para el obispo. De estas cantidades los mediorracioneros percibían 12.000 maravedís. Esta tradición continuaba siendo confirmada por los reyes sucesivos hasta la llegada de los Reyes Católicos que, sin aumentar dicha renta, ordenaron que los sábados se celebrase la misa con una mayor solemnidad en el altar de la Salve Regina, teniendo que asistir todo el cabildo y el obispo. También los domingos, antes de las vísperas, tenían que realizar una procesión rezando la letanía y oraciones. Se estableció, además, cada mes, un aniversario por las almas de los reyes y sus sucesores. Para dicha ocasión, colocaban sobre la tumba de Alfonso X una 
capa de brocado y una corona de rey de plata dorada, que se utilizaba solamente para esta ceremonia y que permanecía guardada en la sacristía ${ }^{26}$.

Los mediorracioneros se quejaban contínuamente de que ellos solos cumplían con lo establecido por los Reyes; el resto de los miembros del cabildo no asistían ni tampoco el obispo. Solicitaban además el aumento a 8 reales por cada misa celebrada, en lugar de los 30 maravedís que percibían. El cabildo replicó que todos asistían en el coro a ofrendar la misa, ya que el que no asistía no ganaba su porción, además de que los mediorracioneros tenían como función principal el decir las misas de particulares y de los reyes y para ello percibían los suficientes emolumentos ${ }^{27}$.

\subsection{Otros prebendados y servidores}

\section{a) Capellanes}

Asistían y servían en el coro y altar mayor de la Iglesia Catedral, tenían a su cargo las capillas existentes en la Iglesia Mayor o en otras situadas en diferentes parroquias. No les competía derecho alguno de gobierno en la Iglesia Catedral, tan sólo el de obedecer a las altas jerarquías del cabildo.

Existía un gran número de capellanes (en 1386 había 39 miembros y en 1474 habían aumentado a 54), cada uno con su correspondiente capellanía, dote, frutos y rentas. De los llamados celebrantes, que poseían el grado de presbítero, tan sólo había 12 a finales del siglo XV. A principios del siglo XVI su número fue aumentado a 16 y en 1543 se incrementó hasta $24^{28}$.

Los 24 capellanes tenían la obligación de asistir y prestar servicio en el coro y altar mayor todas las horas diurnas y nocturnas. Debían ser sacerdotes y celebrar de ordinario misa. De este grupo saldrá el mayor número de mediorracioneros, ya que solían estar preparados en lectura y canto. Poseían su propia mesa y procurador, un libro y un mayordomo encargado de escribir cada día los que tuviesen que ir a las horas canónicas y misa en el coro de la Iglesia Catedral.

\footnotetext{
${ }^{26} \mathrm{ACM}$, leg. 543, n. 52. Carta desde Madrid al deán y cabildo de Cartagena, 15-9-1586.

${ }^{27} \mathrm{ACM}$, leg. 467, sin numerar, 17-6-1588.

${ }^{28} \mathrm{ACM}$, leg. 31, n. 20.
} 
Dentro de los capellanes estaban los denominados del número y que podían ser presbíteros o no. Se sentaban durante las horas y oficios divinos en las sillas más prominentes de la estancia baja de dicho coro; y así mismo iban en los lugares más destacados de las procesiones, no pudiéndose mezclar con los demás capellanes. Estaban repartidos por coros de manera que el Obispo tenía su coro de capellanes y el deán otro, ambos con el mismo número de componentes.

Después estaban los denominados de coro y en los que había también presbíteros, diáconos, subdiáconos y acólitos. Se sentaban en un lugar inferior a los del número, así como también ocupaban una posición menos destacada en las procesiones. Los presbíteros ocupaban los primeros lugares, seguidos de los diáconos, subdiáconos y acólitos. En el caso de que todos fuesen de misa debían ocupar sus posiciones dependiendo de cuando tomaron sus capellanías ${ }^{29}$.

A partir de estas dos clases, existía un número variado de capellanes que no asistían a los oficios del coro y que podían ocuparse de otras tareas religiosas fuera del propio ámbito del coro de la Catedral.

b) Cantores e infantes de coro

En la Iglesia Catedral había un número superior a los 20 cantores. Cobraban diferentes salarios, según su mayor o menor papel dentro del coro, debiendo asistir junto con el maestro de capilla, a todas las fiestas, celebraciones solemnes y procesiones realizadas en la Iglesia Mayor.

Había también 12 mozos o infantes de coro que debían poseer buenas voces para su servicio en el coro, altar mayor y capilla de música. El salario de todos ellos era aportado por las mesas capitular, episcopal y la fábrica.

\section{c) Sochantre}

Estaba bajo la subordinación del chantre del que cobraba su salario y tenía que entonar todos los oficios y antífonas, así como dar voz y tono al coro. Era el encargado de realizar las tablas donde se especificaban los nombres de los mediorracioneros que debían decir las misas cada semana.

\footnotetext{
${ }^{29} \mathrm{ACM}$, Ac. Cap. 1515-1543, fol. $71 \mathrm{r}$.
} 
d) Maestro de capilla

Dirigía el coro de la Catedral y se encargaba de que se efectuasen los cantos establecidos por el cabildo en el coro. También de componer, o mandar componer, cantos para fechas determinadas como villancicos durante la Navidad. Debía dar lecciones diarias a los mozos del coro, especialmente de canto llano y de órgano, distribuídas de la siguiente manera: por la mañana dos horas y por la tarde otras dos horas. Podían asistir a sus clases los capitulares que quisieran aprender acompañados por dos criados, así como todos los beneficiados y capellanes de la Iglesia Catedral. No debía percibir sueldo alguno por la asistencia de mayor o menor cantidad de personas, a no ser que los asistentes lo diesen por su voluntad.

Estaba encargado del órgano y tenía la obligación de asistir a todas las fiestas y procesiones celebradas en la Iglesia Catedral, al igual que los cantores y ministriles. Los cantores no podían ir ni concertar su asistencia a los entierros y honras fúnebres sin el maestro de capilla o con su permiso.

\section{e) Nuncio pertiguero}

Era un ministro y oficial del cabildo de carácter secular y cuya misión consistía en encabezar las procesiones que se realizaban en la Catedral. Además, debía custodiar las puertas del lugar donde se celebraba cabildo y las del Coro cuando se realizaban los oficios divinos. Estaba encargado de llamar y hacer entrar en las reuniones del cabildo a las personas que habían sido elegidas para algún beneficio ${ }^{30}$.

No era un oficio vitalicio, sino que permanecía en su puesto por el "tiempo que fuere voluntad del cabildo". Los requisitos requeridos para tal cargo era ser cristiano viejo e hijodalgo, además de un hombre honrado y de bien. Los encargados de elegir a la persona más idónea para el oficio eran los miembros del cabildo y el obispo, o su provisor en su lugar, que aportaban su salario compuesto por: 6 cahices de trigo, 4 tinajas de vino de 20 arrobas sacadas cada una de los graneros de la ciudad de Murcia. Además percibía 2000 maravedís anuales por la vigilia de Navidad del mayordomo

\footnotetext{
${ }^{30} \mathrm{ACM}$, leg. sin catalogar, año 1533 . Trata sobre las diferencias entre obispo y cabildo ante la elección del nuncio pertiguero.
} 
de las iglesias parroquiales de Murcia. Cada vez que entraba un nuevo beneficiado a formar parte de la Catedral, el nuncio recibía una cantidad de dinero:

-Si era una nueva dignidad: 600 maravedís.

-Si era un nuevo canónigo: 300 maravedís.

-Si era un nuevo racionero: 150 maravedís

-Si era un nuevo mediorracionero, diácono y subdiácono: 100 maravedís.

Su salario permaneció estable durante, prácticamente, todo el siglo XVI y también para la elección de este cargo se planteó la cuestión de si el obispo, o su provisor en su nombre, tenía derecho a entrar en las reuniones del cabildo. Hasta el año 1557 el obispo no intervino directamente, sino que los miembros capitulares lo elegían y luego él en su casa daba su aprobación y conformidad. Es a partir del año 1557, con la elección de Hernando de Valdelvira, cuando se produce una votación directa del obispo. La oposición de algunos miembros del cabildo fue grande y no dudaron en llevar el caso ante la Chancillería de Granada ${ }^{31}$.

\section{f) Sacristán mayor}

Varias personas eran las encargadas de mantener en perfecto estado todo lo depositado en la sacristía de la Iglesia Catedral. Entre las funciones y obligaciones que tenía que llevar a cabo el sacristán mayor están: tener dos mozos, uno de ellos eclesiástico, para llevar el incienso y servir en el altar, cuidar de que los objetos y ornamentos de la Iglesia y del altar estuvieran bien custodiados, limpios y en orden, encender las lámparas de la iglesia, ocuparse de las capas de los capitulares, procurar el vino para las misas, comprar la cera para los cirios y velas, vivir en la iglesia para hallarlos allí, por si ocurría alguna necesidad de administrar los últimos sacramentos u otra incidencia, tañer las campanas, barrer y regar la iglesia, poner i quitar las esteras.

\footnotetext{
${ }^{31}$ Ibidem.
} 


\subsection{Otros cargos de tipo administrativo}

\section{a) Fabriquero mayor}

Persona encargada de la administración y rentas de la fábrica de la Iglesia Catedral. Debía arrendar, recibir, cobrar todas las rentas pertenecientes a dicha fábrica, dar cartas de pago y aparecer en juicio. El cargo no era vitalicio, sino que se renovaba cada 3 años por Navidad entre los diferentes componentes del cabildo. El saliente tenía que presentar cuenta de su gestión ante los miembros del cabildo: "con pago de lo que oviere recebido e gastado por la dicha Iglesia, e que de los dineros que abrá recebido e cobrado e gastado fasta el dia que diere la dicha cuenta"32.

Si mostraba sus cuentas con deudores que no habían pagado durante su mandato, tenía que justificar que había realizado todas las acciones pertinentes para cobrarles. Al mismo tiempo que se producía la elección del nuevo fabriquero se elegía a dos personas del cabildo, que daban su parecer y consejo al fabriquero sobre los asuntos de las rentas que se tenían que arrendar, en las obras a realizar en la Iglesia, etc. En el caso de una obra de gran envergadura o un importante negocio se precisaba el parecer del obispo, deán y cabildo. Terminados los 3 años, el fabriquero podía renovar su cargo por otro tiempo, siempre y cuando su gestión hubiese sido buena.

b) Alcalde mayor de Alcantarilla y Alguazas.

Las villas de Alcantarilla y Alguazas pertenecían al obispo de Cartagena, que tenía sobre ellas plenas competencias señoriales y jurisdiccionales al estar configuradas dentro de un señorío eclesiástico. El obispo y el cabildo catedralicio, como verdaderos señores que eran sobre estas tierras, se encargaban de nombrar a un alcalde mayor para ambas villas. Dicha elección se realizaba por votación en las sesiones de cabildo, teniendo la persona elegida todo el poder de los miembros capitulares y del Obispo para "oyr, difinir y sustentar todas las causas y pleytos ansy ceviles como crimynales" 33 .

\footnotetext{
${ }^{32}$ ACM, Ac. Cap. 1515-1543, fol. 75 r.

${ }^{33} \mathrm{ACM}$, Ac. cap. $1515-1543$, fols. 341 v. -342 r.
} 
El salario procedía de las penas y condenas puestas en las dos villas y por partes iguales. Si el nuevo oficial no cumplía bien su cargo, o si se ocasionaban excesos, podía ser cesado en sus funciones por mandato del obispo y cabildo, que actuaban como verdaderos señores temporales $\mathrm{e}$ intentaban mantener el orden y la justicia dentro de su señorío. Al mismo tiempo que exigir un orden y cumplimiento de sus mandamientos, también reclaman una protección y cuidado de sus vasallos.

c) Mayordomo de prima y grossa

Era el mayordomo mayor de todas las rentas que pertenecían y formaban parte de la mesa capitular. La persona elegida para el cargo debía saber arrendar y cobrar todas las rentas de la mesa capitular, cobrar los maravedís que cada año se obtenían de las rentas reales del almojarifazgo de la ciudad de Murcia, dar cartas de pago y finiquito, comparecer en los juicios que se produjesen a los que fuese requerido. Generalmente, el mayordomo era renovado cada tres años y elegido de entre los miembros del cabildo: canónigos, racioneros o mediorracioneros. Debía de efectuar salidas por todo el obispado acompañado por otros miembros del cabildo como ayudantes para hacer inspección por todos los graneros y rentas. El cabildo le asignaba una cantidad de dinero para que sufragase los gastos de los viajes y de su manutención.

\section{d) Mayordomo del libro del punto}

Estaba encargado de llevar al día y en perfecto orden el libro del punto de las horas del coro, de anotar en él cualquier negligencia cometida por los mediorracioneros, capellanes u otro miembro del coro y cabildo, las posibles riñas o discusiones, las faltas de asistencia, etc.

Este cargo, como el anterior, era de nombramiento anual aunque renovable y ocupado por un miembro del cabildo. En muchas ocasiones, debido a que nadie quería desempeñar dichos cargos, se tienen que hacer las elecciones a suerte y sin poder negarse a cumplir con la ocupación designada. 


\section{e) Fiel del granero}

Denominado también mayordomo del granero, se encargaba del granero mayor de la ciudad de Murcia que pertenecía al obispado. Debía llevar buena cuenta de todo el trigo y cebada que entraba y salía, el vino, el aceite y otro cualquier producto allí almacenado. Era desempeñado por miembros capitulares y con carácter anual, aunque podía renovarse en la misma persona.

Otros cargos eran: el colector del subsidio y excusado, los visitadores de las heredades y casas del cabildo, el mayordomo del hospital general de Murcia, el visitador del hospital, contadores para cuentas y repartimientos del subsidio, contadores para las cuentas de los capellanes del número,encargados de las llaves del archivo, obrero de las casas, visitadores del granero, solicitador de los negocios comunes. Con esta lista de cargos, todos los componentes del cabildo catedralicio tenían un trabajo a realizar desde el punto de vista económico y administrativo. No cumplían tan sólo con deberes religiosos como eclesiásticos que eran, sino que, además, debían de procurar el buen funcionamiento de su institución, ya que de ella se mantenían. Cuanto mayores fuesen sus ingresos, mayores eran sus salarios y nivel de vida. Siempre serán continuas las quejas de la pobreza de sus ingresos y de los salarios de sus componentes.

En una escala inferior, existía un grupo de personas empleadas en la Iglesia Catedral que podían ser eclesiásticas o no y cuya misión era ocuparse de la limpieza y mantenimiento, así como prestar diferentes funciones para ella: perrero, pregonero, los limpiadores, cerero, etc.

\subsection{Los oficiales de la escribanía y audiencia episcopales}

a) El notario

Encargado de escribir y autentificar los documentos emanados de la escribanía episcopal y capitular, así como de consignar por escrito los acuerdos del cabildo en los libros de actas capitulares (siempre y cuando fuera nombrado como secretario capitular). El número de éstos empleados no era fijo, aunque sí abundante. En la mayoría de los casos tenían la condición de clérigos y el oficio de notario no era un cargo vitalicio dentro 
de la escribanía y audiencia episcopales. Su elección y nombramiento como notario apostólico dependía del obispo ${ }^{34}$.

b) El provisor

El provisor general del obispado era la persona encargada de actuar en nombre del obispo cuando éste se encontraba ausente, o si le delegaba alguna cuestión. Además de él existían en la propia audiencia, así como por toda la diócesis cartaginense, una serie de provisores y jueces encargados de impartir justicia y hacer defender la jurisdicción eclesiástica. Tenía que procurar ajustarse a los aranceles establecidos por el prelado, así como de no aceptar regalos ni presentes de las personas sometidas a juicio, o que interviniesen en ellos indirectamente, ni cualquier obsequio o dinero de los propios oficiales de la audiencia episcopal. Debían evitar entregar mandamientos en blanco para no dar lugar a posibles falsificaciones, no consentir que a un mismo procesado se le hiciese más de un proceso por el mismo delito, castigar los delitos públicos como eran los juegos, amancebamientos, blasfemias, usura, etc. Los jueces no podían recibir en su poder las penas de cámara ni de obras pías, sino que los notarios las debían de asentar en los libros del receptor. Tenían que visitar las cárceles, al menos un día a la semana, y ser informados de los presos, los delitos cometidos, el tratamiento recibido, la salida y entrada de la cárcel de los encarcelados, etc. Iban anexos los cargos de provisor y vicario general del obispado pero, en período de sede vacante, se nombraba además de un provisor a otra persona diferente como vicario.

\section{c) El fiscal}

Este oficial era el encargado de acusar y denunciar en la audiencia episcopal los delitos cometidos y era requisito imprescindible para trabajar como tal el ser sacerdote. En su comportamiento debía estar presente la buena fe y no aprovecharse de su cargo para culpar a las personas por

\footnotetext{
${ }^{34}$ Ver más ampliamente en los artículos de María José OLIVARES TEROL, Los notarios de la escribanía y audiencia episcopales de la diócesis cartaginense durante el siglo XVI, "Murgetana", 88 (1994), pp. 103-125; Francisco Reyes MARSILLA DE PASCUAL, Introducción al protocolo eclesiástico de Juan Sánchez, notario apostólico de Murcia, siglo XV, "Miscelánea Medieval murciana", 18 (1993-1994), pp. 77-93.
} 
motivos personales o de una manera maliciosa. Del mismo modo que los jueces, tenían que prestar juramento al tomar el cargo de obedecer y guardar fidelidad al obispo; así como no aceptar ningún regalo para trabajar libremente y sin presiones ni fraudes de ningún tipo. Debían ser obedecidos por todos los clérigos a sus requerimientos y, de este modo, no obstruir a la justicia. Estaban obligados a llevar un libro de registro para anotar todas las faltas y delitos comprobados a los clérigos de la diócesis, recibir las denuncias debidamente firmadas o identificadas de las personas que las hacían, ya que, en caso contrario, no debían pasar el caso ante los jueces y así evitar acusaciones sin una justificación legal. Su asistencia a todas las audiencias públicas era obligatoria, a no ser por motivos importantes y con la presentación de la correspondiente licencia del provisor.

No era un cargo vitalicio sino que podía ser revocado su nombramiento por diferentes motivos:

- Por decisión de los miembros capitulares, cuando se procedía en la vigilia de Navidad a la designación de los nuevos oficiales; algunos continuaban si habían llevado bien su gestión pues, en caso contrario, eran destituidos.

- Con la llegada de un nuevo obispo, cesaban a todos los oficiales y unos eran nuevamente nombrados y otros substituidos.

d) Los ejecutores

También recibían el nombre de alguaciles y estaban encargados de prender a los acusados y de ejecutar las sentencias fijadas por los jueces. $\mathrm{Si}$ los culpados eran clérigos, tenían que llevar mucha discreción para evitar el escándalo y la publicidad. Les estaba prohibido aceptar regalos por su trabajo y no dar lugar así a los fraudes y presiones ni maltratar y hacer vejaciones a los apresados. Debían realizar rondas para ver si las tiendas estaban cerradas los domingos, si la gente no trabajaba a la hora de los oficios divinos y en caso contrario denunciarlos. No podían ser acompañados por la justicia seglar al ir a prender a alguien sin un mandamiento expreso del juez; especialmente si se trataba de un clérigo el inculpado.

e) Los nuncios

También denominados cursores, tenían que ser personas de buena fama, pacífica aprobación y conciencia. Estaban encargados de citar a las 
personas solicitadas por la Audiencia episcopal, tanto si eran de la ciudad como de todo el obispado, y en tal caso ellos mismos tenían que desplazarse a los lugares de los solicitados, siendo los gastos del viaje sufragados por la audiencia.

f) El alcaide de la cárcel

De él dependía el buen funcionamiento de la cárcel y el tratamiento a los presos que oyeran misa todos los días y fiestas de guardar, que no tuvieran armas, mantener a las mujeres en celdas separadas y aisladas de los hombres, procurar que el edificio estuviera limpio y cerrado, prohibir las visitas de mujeres a no ser que fueran las madres, hermanas o esposas de los presos aunque siempre guardando las distancias.

Debía llevar un libro de registro en el cual tener apuntados los nombres de los presos. No podía tampoco aceptar regalos, conceder privilegios a los presos, así como maltratarlos ni causarles vejaciones. Quedaba bajo su entera responsabilidad el buen funcionamiento de las cárceles y el mantenimiento y trato a los presos, pues en caso contrario tenía que atenerse a las penas correspondientes puestas por los jueces. El cargo, como en los anteriores casos, quedaba anulado en sede vacante y se producían nuevos nombramientos que podían recaer en la misma persona o en otra.

\section{SEDE VACANTE}

El cabildo catedralicio, además de desempeñar las funciones de apoyo y consejo al prelado, entre otras cosas, tenía la misión principal de actuar como cabeza rectora de su diócesis. Esto sucedía en los períodos de tiempo en los cuales no existía un prelado como titular y hasta su llegada y toma de posesión, bien personalmente o por poderes, se encargaba de toda la administración, tanto temporal como eclesiástica, de la diócesis. La opción de posesión por poderes es la que se presenta en casi todos los casos del episcopado murciano. En tal caso y ante su ausencia, el obispo nombra a un provisor para que cumpla sus funciones en su nombre.

Una vez declarada la sede vacante, el cabildo revocaba todos los nombramientos de los oficiales: provisores, visitadores, fiscales, notarios, alguaciles, vicarios, arciprestes, fieles de las tercias y frutos decimales, etc. 
Efectuadas las anulaciones el cabildo debía de nombrar a otras personas, o a las mismas en algunos casos, para que ocupasen dichos puestos. Después de realizada la toma de posesión, el prelado entrante los volvía a cambiar o a mantener, según lo considerara oportuno.

El deán y cabildo debían de guardar unas disposiciones sobre el nombramiento de oficiales en los períodos de sede vacante:

El collector puesto por la Camara Apostolica solo tiene la administraçion de los frutos perteneçientes a la obispalia como uno de los ynteresados en ellos; los quales los arrienda o benefiçia como mejor le pareçe y combiene a la Camara Apostolica. Los derechos del sello los lleva el provisor. En sede vacante no ay condenaçiones para la Camara sino para obras pias y gastos de justiçia. Limosnas en sede vacante no se hazen de la mesa episcopal ni menos estando absente el obispo, solo se paga de la dicha mesa episcopal en sede vacante la parte de salario de los cantores y ministriles, maestro de capilla y organista, que es lo que los obispos acostumbran y tiene obligacion de pagar en esta Yglesia y es la terçia parte de todos los dichos salarios, porque las otras dos las paga el cabildo y fabrica ${ }^{35}$.

Estos espacios de tiempo vacantes no solían ser muy tranquilos para los cabildos catedralicios, debido a las constantes intromisiones de los representantes de la cámara apostólica a la hora de proveer los oficios, mayordomías y otros asuntos.

Como conclusión a este trabajo, podemos decir que, a finales de la Edad Media, la Iglesia de Cartagena-Murcia está plenamente consolidada, con un cabildo catedralicio que mantendrá unas mismas estructuras y composición desde sus inicios hasta bien entrada la Edad Moderna y con un poder económico que aunque dentro del reino de Murcia es indiscutible $e^{36}$, sin embargo, en relación con el que disponen otras diócesis, deja mucho que desear. Nuestros planteamientos iniciales, que hemos intentado llevar en todo nuestro trabajo de investigación, eran plasmar al cabildo murciano como institución (su origen y composición) pero sin llegar a pretender adentrarnos en consideraciones de tipo económico (propiedades, rentas, censos, etc).

\footnotetext{
${ }^{35} \mathrm{ACM}$, leg. 12 , n. 5.

${ }^{36}$ Idea resaltada constantemente por RODRÍGUEZ LLOPIS y GARCÍA DíAZ, Iglesia y sociedad, Murcia, 1994.
} 


\section{RÉSUMÉ}

En 1250, le pape Inocencio IV érige le diocèse de Cartagena-Murcia à demande du roi Fernando III et de son fils Alfonso. Sa première localisation est la ville de Cartagena, bien que dans l'année 1289 passe à Murcia après la bulle accordée par Nicolas IV. Le nombre des composants du chapitre varie un peu dès XIII ${ }^{e}$ siècle jusqu'au $\mathrm{XVI}^{\mathrm{e}}$ siècle. Le nombre de bénéficiers qui devaient résider dans le choeur pour le service du maitre-autel de la Cathédrale était de 62 , en total. Dans les périodes d'évêché vacant, le chapitre devait procéder comme tête du diocèse.

\section{SUMMARY}

In 1250 , pope Inocencio IV put up the bishopric of Cartagena-Murcia at the request of the king Fernando III and their son, Alfonso. Their first location had been the city of Cartagena, although in 1289 it was transferred to Murcia, after the granted bull of Nicolas IV. The number of members of the ecclesiastic chapter changed a little from the XIIIth century till the XVIth century. The beneficiaries that should reside in the choir for the Cathedral's high altar service and ministry were 62 . The ecclesiastic chapter had to act as the head of the diocese in the periods of vacant bishopric. 